\title{
Educação Médica em tempos de pandemia e a utilização de metodologias ativas mediadas por tecnologia
}

\author{
Medical education in pandemic times and technology-mediated active \\ methodologies
}

Ana Carolina de Melo ${ }^{1}$ (D) Caroline Valente ${ }^{2}$ (D), Daniela Maysa de Souza ${ }^{1}$ (D),

Keila Zaniboni Siqueira Batista² (D), Ricardo Dantas Lopes ${ }^{1}$ (D), Sara Cristiane Barauna²

\begin{abstract}
RESUMO
O objetivo deste relato de experiência é apresentar a utilização de metodologias ativas mediadas por tecnologia em tempos de pandemia na disciplina Integração Básico-Clínica II do curso de Medicina. A experiência é caracterizada como uma possibilidade de contribuição ao desenvolvimento docente para o mundo pós-pandemia. Em um grupo de cinco professores e 40 estudantes, a disciplina Integração Básico-Clínica II foi adaptada emergencialmente para atividades mediadas por tecnologia. Os conteúdos trabalhados propiciaram a integração dos conhecimentos disciplinares à clínica e trouxeram inúmeros desafios pedagógicos neste momento inédito de como ensinar, aprender e sobreviver a uma pandemia. Em 16 encontros via plataforma institucional foram utilizadas exclusivamente metodologias ativas de ensino-aprendizagem, com estratégias diversificadas. O modelo de aprendizagem virtual não é algo novo, apesar de inédito para esse grupo de discentes e para esta disciplina e seu valor está em possibilitar repensar a educação e seus mecanismos, num extenuante exercício de criatividade para enfrentar novos desafios surgidos decorrentes de situações extremas. A aplicação de metodologias ativas associado ao feedback dos discentes foi imprescindível para a tomada de decisões na continuidade da integração dos conteúdos, levando à construção de uma disciplina agradável e que contribuiu para o processo formativo de todos os envolvidos. O maior aprendizado foi a necessidade de adaptação e criatividade, permitindo contribuições à construção da identidade docente. A práxis foi fortalecida e reinventada, sendo a adaptação e criatividade, atributos considerados necessários para o desenvolvimento docente para o mundo pós-pandemia.
\end{abstract}

Palavras-chave: Educação médica, Metodologias e ferramentas baseadas nas TIC, Aprendizagem on-line

\begin{abstract}
This experience report aims to present the use of active methodologies mediated by technology in times of pandemic in the discipline Basic-Clinical Integration II of the medical course. The experience is characterized as a possibility to contribute to the development of professors in the post-pandemic world. In a group with five professors and 40 students, the Basic-Clinical Integration II discipline was adapted on an emergency basis for activities mediated by technology. The contents studied enabled the integration of disciplinary knowledge to the clinic and posed numerous pedagogical challenges in this unprecedented moment of how to teach, learn, and survive a pandemic. In 16 meetings via the institutional platform, active teaching-learning methodologies were used, with various strategies. The virtual learning model is not new, although unique for this group of students and this discipline. Its value lies in the possibility to rethink education and its mechanisms in a laborious exercise of creativity to face new challenges arising from extreme situations. The application of active methodologies associated with feedback from students was essential for the decision-making in the continuity of the integration of the components, leading to the construction of a pleasant discipline that contributed to the training process of all involved. The greatest learning was the need for adaptation and creativity, allowing contributions to the construction of the teaching identity. Praxis was strengthened and reinvented, and adaptation and creativity were considered necessary skills for teaching development in the post-pandemic world.
\end{abstract}

Keywords: Medical education, Medical informatics applications, online learning.

1Universidade Regional de Blumenau. Departamento de Medicina.

2Universidade Regional de Blumenau. Departamento de Ciências Naturais. 


\section{INTRODUÇÃO}

As mudanças no contexto do ensino médico, estimuladas pelas Diretrizes Curriculares Na-cionais (DCNs) ${ }^{1}$, incentivam a formação médica crítica, reflexiva e interprofissional, e são um de-safio que todas as escolas médicas brasileiras enfrentam. Para reformular um currículo vigente é necessário quebrar velhos paradigmas no ensino em saúde e buscar renovação e introdução de metodologias ativas (MA) que venham de encontro à realidade e demanda dos estudantes ${ }^{2,3}$.

Assim, no ano de 2019, no curso de medicina da Fundação Universidade Regional de Blumenau (FURB) foi criado um eixo de disciplinas integralizadoras, que permeia o ciclo básico entre a primeira e quarta fase, a chamada Integração Básico-Clínica (IBC) ${ }^{4}$. As IBCs têm a proposta de trabalhar de forma interdisciplinar as disciplinas das fases, aproximando estudantes e professores do ciclo básico com a prática clínica, utilizando exclusivamente MA.

Frente ao atual quadro de pandemia do coronavírus (Covid-19), tornou-se necessário buscar novas estratégias para trabalhar na disciplina. As aulas precisaram ser alteradas, em virtude do isolamento social, e uma proposta educacional inovadora precisou ser implementada, com a utilização de MA em aulas mediadas exclusivamente por Tecnologia Digitais de Informação e Comunicação (TDICs), que ocorreu de forma síncrona.

Esse ano letivo veio cheio de incertezas e desafios, que demandaram empenho da instituição, assim como dos docentes e discentes, onde todos tiveram que se adaptar às aulas mediadas por tecnologia. As preocupações com o contato físico e o distanciamento social abalaram emocionalmente estudantes e professores que precisaram se adaptar para suprir a ausência da sala de aula ${ }^{5}$. O desgaste psicológico do estudante de medicina foi ainda mais significativo, pois o estresse gerado pela diminuição das relações sociais e a dificuldade de conciliar a vida acadêmica com a pessoal, assim como a carga excessiva de estudos, foram fatores que contribuíram para esse quadro ${ }^{6}$.

Sabe-se que os efeitos profundos dessa doença podem mudar para sempre a forma como os futuros médicos são educados, sendo importante destacar que as aulas on-line não limitaram ou prejudicaram a educação médica, e sim, estimularam a adesão dos docentes e discentes ao uso de TDICs no processo de ensino-aprendizagem ${ }^{7}$. A diversificação de métodos de ensino, com a introdução de atividades inovadoras, contribuiu para a criação de um cenário propício ao aprendizado. E para obter êxito neste processo de aprendizagem, torna-se necessária a criação de uma rotina de estudos para garantir resiliência aos estudantes, permitindo adaptação a essa nova realidade, com uma nova forma de ensino ${ }^{5}$.

Diante disso, considera-se o uso das MA, associado às TDICs, um elemento fundamental na formação médica em tempos de pandemia, o que possibilita refletir sobre como um fator dificultador, considerando o contexto da ausência das aulas presenciais, pode ser ressignificado, levando a resultados positivos, propiciando uma transformação no ensino médico na FURB.

Desta forma, o objetivo deste relato de experiência é apresentar a utilização de MA na disciplina Integração Básico-Clínica II, mediada por tecnologia, em tempos de pandemia. A experiência caracteriza-se como uma possibilidade de contribuição ao desenvolvimento docente para o mundo pós-pandemia, considerando que a proposta se constituiu de um espaço de formação docente, requerendo adaptação, empatia, planejamento e engajamento de todos os envolvidos, o que possibilitou a expansão da expertise docente.

\section{RELATO DE EXPERIÊNCIA}

A disciplina IBC, da segunda fase de Medicina possui três créditos teóricos semanais, organizados em 18 semanas letivas, além da disponibilidade de uma hora/aula semanal de tutoria de cada docente para esclarecimento de dúvidas.

Seu objetivo é propiciar ao discente o desenvolvimento do raciocínio clínico através do trabalho em equipe e discussão de casos clínicos e situações problemas simuladas, contendo disparadores de aprendizagem que potencializem a integração dos conteúdos das cinco disciplinas do ciclo básico que compõem a segunda fase: Anatomia; Histologia/Embriologia; Bioquímica Meta- 
bólica; Microbiologia e Imunologia. Para alcançar estes propósitos, a disciplina utiliza exclusivamente MA, com estratégias diversificadas.

No semestre letivo 2020/I, que originou este relato de experiência, a turma era composta por 40 estudantes e participaram da disciplina cinco professores, chamados tutores (docentes das disciplinas ofertadas no semestre letivo) e os estudantes foram divididos em oito grupos, sendo um grupo para cada tutor.

Nas reuniões iniciais de planejamento, os tutores, que não haviam trabalhado em conjunto ainda, participaram de uma formação docente conduzida pela coordenadora da disciplina, com formação em MA, versando sobre a utilização de MA na área da saúde. A proposta inicial seria a de realizar a formação docente paralelamente ao semestre letivo, ou seja, a cada estratégia de aprendizagem definida, o grupo de docentes seria capacitado e de forma colaborativa, cada docente, com seus saberes, contribuiria para a execução das atividades propostas.

Para conduzir as atividades, a coordenadora ficou responsável pela organização da disciplina, e rotineiramente seguia-se este fluxo: a docente solicitava as produções, com a orientação pedagógica das atividades propostas e realizava a formação docente sobre a estratégia elencada, de acordo com a necessidade dos docentes. Além disso, cada professor produzia o guia do tutor, contendo brevemente os objetivos de aprendizagem e os tópicos que os estudantes teriam que responder/pesquisar, norteando assim, a condução das atividades pelo tutor.
A partir desta formação inicial, as atividades do semestre foram organizadas, definindo os temas versus a estratégia pedagógica, para as 18 semanas letivas. Os temas foram definidos a partir de uma atividade interativa via aplicativo no primeiro dia de aula, propiciando a integração dos conhecimentos disciplinares à clínica.

Entretanto, com o início da quarentena, somente duas semanas de aula aconteceram presencialmente e as atividades, bem como os encontros de formação docente e as reuniões de planejamento foram mediados por tecnologia, utilizando os recursos do Microsoft Teams $®$.

Esta nova sala de aula, mediada por tecnologia, com interação síncrona, desconhecida e pouco utilizada/vivenciada por muitos discentes e docentes que percorriam uma trilha formativa em um currículo presencial, trouxe inúmeros desafios pedagógicos. Incluindo a necessidade de mediação, empatia, criatividade e acolhimento das demandas, priorizando a manutenção da saúde física e mental de todos os envolvidos, neste momento histórico e inédito de como ensinar, como aprender e como sobreviver a uma pandemia.

Teve-se um cuidado com a seleção das estratégias de ensino, que foram escolhidas de modo a não cansar os estudantes (evitando-se utilizar estratégias de ensino repetidas ${ }^{1}$ ) e contribuir assim, para minimizar a resistência à $M A$, que também foi migrado para o ambiente virtual de aprendizagem.

O Quadro 1 apresenta a organização do semestre letivo contendo os ajustes para o ensino mediado por tecnologias, com uma breve explicação sobre as atividades ofertadas. 
Quadro 1: Organização de conteúdo e estratégias de ensino da disciplina IBC II

\begin{tabular}{|c|c|c|c|}
\hline Semana & Conteúdo/tema & $\begin{array}{l}\text { Estratégia de } \\
\text { ensino }\end{array}$ & Detalhamento das atividades \\
\hline 1 & $\begin{array}{l}\text { Danos decorrentes } \\
\text { da obesidade }\end{array}$ & $\begin{array}{l}\text { Aplicativo Menti- } \\
\text { meter }\end{array}$ & $\begin{array}{l}\text { Via Mentimeter foi solicitado aos estudantes que escrevessem } \\
\text { palavras-chave, relacionadas aos temas que pudessem integrar } \\
\text { os conteúdos das disciplinas da fase (Figura 1). Após, a primeira } \\
\text { atividade (seminário) foi lançada. }\end{array}$ \\
\hline 2 & $\begin{array}{l}\text { Danos decorrentes } \\
\text { da obesidade }\end{array}$ & Seminário & $\begin{array}{l}\text { Apresentação dos seminários. } \\
\text { Avaliação } 1\end{array}$ \\
\hline 3 & $\begin{array}{l}\text { Aula suspensa de- } \\
\text { vido à quarentena }\end{array}$ & $\begin{array}{l}\text { Reposição na sema- } \\
\text { na } 14\end{array}$ & $\begin{array}{l}\text { Planejamento docente remoto, adaptação para o ambiente } \\
\text { virtual. }\end{array}$ \\
\hline 4 & Coronavírus & Seminário & Orientações e preparo da atividade. \\
\hline 5 & $\begin{array}{l}\text { Procedimentos } \\
\text { Cirúrgicos }\end{array}$ & $\begin{array}{l}\text { Cinesaúde com } \\
\text { Estudo de caso }\end{array}$ & $\begin{array}{l}\text { Após assistirem ao filme Mãos Talentosas, receberam questões } \\
\text { para o estudo de caso. }\end{array}$ \\
\hline 6 & Coronavírus & Seminário & $\begin{array}{l}\text { Apresentação dos seminários. } \\
\text { Avaliação } 2\end{array}$ \\
\hline 7 & $\begin{array}{l}\text { Procedimentos } \\
\text { Cirúrgicos }\end{array}$ & $\begin{array}{l}\text { Cinesaúde com } \\
\text { Estudo de caso }\end{array}$ & $\begin{array}{l}\text { Apresentação da resolução do estudo de caso da semana } 5 \text {. } \\
\text { Avaliação } 3\end{array}$ \\
\hline 8 & Feriado & & \\
\hline 9 & Hepatocarcinoma & Gamificação & $\begin{array}{l}\text { Foram apresentadas situações problemas } x \text { tomada de decisão e } \\
\text { cada escolha representava uma consequência clínica ao paciente } \\
\text { e a pontuação na questão em análise. } \\
\text { Avaliação } 4\end{array}$ \\
\hline 10 & $\begin{array}{l}\text { Tireoidite de } \\
\text { Hashimoto }\end{array}$ & $\begin{array}{l}\text { Problem-Based } \\
\text { Learning } \\
\text { (PBL) }\end{array}$ & $\begin{array}{l}\text { Em pequenos grupos, os estudantes pontuavam os problemas } \\
\text { listados no caso clínico apresentado e, posteriormente na busca } \\
\text { individual, realizaram as pesquisas. }\end{array}$ \\
\hline 11 & Leptospirose & $\begin{array}{l}\text { Team Based Lear- } \\
\text { ning (TBL) }\end{array}$ & $\begin{array}{l}\text { Os estudantes receberam um texto base e após, realizaram um } \\
\text { exercício de múltipla escolha individual e na sequência, as es- } \\
\text { colhas foram discutidas entre os integrantes das equipes. Após, } \\
\text { mediado pelo tutor, as equipes debateram entre si, promovendo } \\
\text { então, um diálogo reflexivo. } \\
\text { Avaliação } 5 \text {. }\end{array}$ \\
\hline 12 & $\begin{array}{l}\text { Tireoidite de } \\
\text { Hashimoto }\end{array}$ & PBL & $\begin{array}{l}\text { Retorno PBL: os achados foram compartilhados e explorados, } \\
\text { seguindo o guia do tutor. Para esta pesquisa, os estudantes soli- } \\
\text { citaram um prazo maior. } \\
\text { Avaliação } 6 \text {. }\end{array}$ \\
\hline 13 & Aborto & Análise Situacional & $\begin{array}{l}\text { Esta estratégia pede um julgamento de possíveis soluções em } \\
\text { que o estudante precisa colocar as opções de respostas em } \\
\text { ordem de prioridade, de acordo com as ações que deve realizar/ } \\
\text { considerar. Seguindo uma sequência de relevância (desde a mais } \\
\text { apropriada até a menos apropriada) e a ordem de cada ação } \\
\text { representa uma pontuação. } \\
\text { Avaliação } 7 \text {. }\end{array}$ \\
\hline 14 & Parto prematuro & TBL & Avaliação 8. \\
\hline 15 & Transplante renal & Aula invertida & $\begin{array}{l}\text { Os estudantes receberam as indicações de leituras, com o tempo } \\
\text { disponibilizado para realização desta atividade. }\end{array}$ \\
\hline 16 & Transplante renal & Aula invertida & Alunos solicitaram mais tempo para o estudo individual. \\
\hline 17 & Transplante renal & Aula invertida & $\begin{array}{l}\text { Retorno aula invertida: as equipes responderam aos questionamen- } \\
\text { tos propostos, com oportunidade de esclarecimento de dúvidas. } \\
\text { Avaliação } 9 .\end{array}$ \\
\hline 18 & $\begin{array}{l}\text { Interpretação de } \\
\text { exames laborato- } \\
\text { riais }\end{array}$ & $\begin{array}{l}\text { Aula expositiva } \\
\text { dialogada }\end{array}$ & $\begin{array}{l}\text { Interpretação e análise de exames laboratoriais }{ }^{2} \text { e a respectiva } \\
\text { integração entre as disciplinas. }\end{array}$ \\
\hline 19 & $\begin{array}{l}\text { Avaliação da dis- } \\
\text { ciplina }\end{array}$ & Avaliação final & $\begin{array}{l}\text { Contextualizado aspectos positivos, negativos e sugestões de } \\
\text { melhorias. }\end{array}$ \\
\hline
\end{tabular}

Fonte: Elaborado pelos autores.

2 Esta temática foi uma necessidade observada na condução dos encontros anteriores, quando os estudantes apresentaram dificuldades para analisar os resultados laboratoriais. Optou-se pelo método tradicional por identificar que os estudantes estavam saturados de atividades ao término do semestre. 
Figura 1: Temas para integração da fase sugeridos pelos estudantes

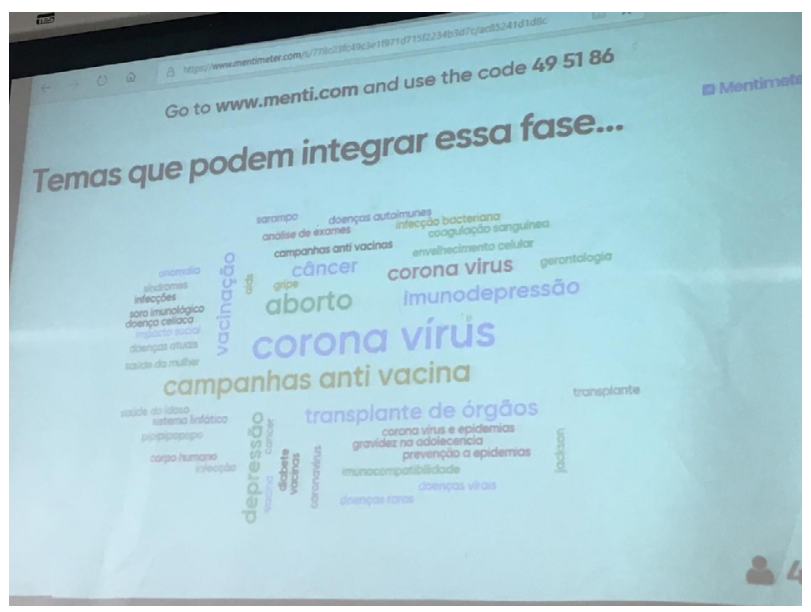

Fonte: Registro dos autores.

Ao total, os estudantes tiveram nove atividades avaliativas que objetivavam garantir a participação, engajamento e presença nos encontros virtuais. Cada tutor era responsável por avaliar seu pequeno grupo, a partir de um instrumento de avaliação, que continha os seguintes itens: Iniciativa, responsabilidade e participação; Qualidade do referencial teórico apresentado; Habilidade comportamental: saber ouvir, respeito ao tempo e trabalho em equipe; Apresentação de novas possibilidades de resolução: autonomia, inovação, comprometimento e práticas de avaliação e feedback.

Os estudantes avaliaram como negativa a grande quantidade de avaliações, com a justificativa de tensão e sobrecarga emocional e, além disso, mesmo com os ajustes realizados no cronograma, consideraram pequeno o tempo destinado à resolução das atividades. Como aspecto positivo indicaram a diversidade de estratégias, principalmente $\mathrm{PBL}$, que estimula o gerenciamento da autoaprendizagem ${ }^{8}$, o TBL e a gamificação. Além do conteúdo disciplinar, os estudantes apontaram a conduta dos tutores, citando o carinho, a compreensão e a solicitude, que foram o ponto-chave para que a disciplina transcorresse com fluidez.

Devido à Covid-19, vivencia-se uma nova era educacional, um período de reinvenção do ensino remoto e das adaptações entre estudantes e professores ao ambiente virtual ${ }^{9}$.

No contexto da medicina, estes estudantes são, em sua maioria, jovens que passaram mui- to tempo em cursos pré-vestibulares, seguindo o modelo tradicional de ensino ${ }^{10}$. Esse padrão de estudo torna-se um modelo pedagógico seguido e, ao entrar na Universidade e deparar-se com disciplinas com MA que integram conteúdos, observa-se estranhamento e em alguns casos, certa resistência ao novo e desconhecido. Nesse sentido, transpor este aprendizado ao ambiente virtual requer ainda mais novas habilidades docentes, como a apropriação de estratégias pedagógicas inovadoras e motivadoras.

Sabe-se que as metodologias tradicionais criam uma sensação de conforto e passividade ao estudante e uma nova proposta de ensino, centrada na autonomia discente é, no mínimo, desafiante. A integralidade das disciplinas se constitui como um fator importante para a motivação do estudante ao aprendizado e auxilia na minimização da resistência dos acadêmicos às $M A^{11}$.

Além do papel do docente, entre as diferentes teorias relacionadas à educação remota, o estudante $^{12}$ é o elemento essencial em qualquer sistema educacional. A análise de suas necessidades (também emocionais) e características específicas são os elementos que condicionam o manejo da tecnologia na educação remota.

A inserção de práticas inovadoras neste momento de ensino remoto emergencial vai ao encontro do espaço de excelência e dos valores de uma Universidade, que oportuniza aprendizado e constante capacidade de inovação ${ }^{13}$. Esta inovação requer motivação e a literatura afirma que estudantes devem ser estimulados ao engajamento efetivo no processo de construção do seu próprio conhecimento, orientados e apoiados pelos profissionais que os acompanham, num trabaIho colaborativo ${ }^{14}$. O grande desafio então é proporcionar tal processo de aprendizagem através das TDICs, ocupando um importante papel para a modernização dos sistemas educacionais e nas formas de aprendizado ${ }^{15}$.

Porém, foi imperioso ir além dos conteúdos e ensinar habilidades. A maior dificuldade foi transpor o ensino presencial (com proximidade e interação com os estudantes), para um modelo virtual desconhecido, sem contato físico, em meio à pandemia e suas consequências. Isso exigiu dos docentes a criação de atividades que possibilitassem a resolução colaborativa de problemas com 
criatividade, contemplando a mesma qualidade de ensino presencial ${ }^{16}$.

O modelo de aprendizagem virtual não é algo novo (mas para esse grupo desta disciplina foi inédito) e seu valor está em possibilitar repensar a educação e seus mecanismos, num extenuante exercício de criatividade, para enfrentar novos desafios surgidos decorrentes de situações extremas.

Na educação virtual, os propósitos educacionais, bem como os resultados, devem ser os mesmos que os presenciais, mas com um olhar atento à avaliação, que deve ser mais flexível ${ }^{11}$. Estas novas alternativas de ensino, que requerem ampla interação discente-docente, possibilitam avanços no processo avaliativo, que deve priorizar a formação e o desenvolvimento dos estudantes no alcance das competências indicadas pelas $\mathrm{DCNs}^{17}$.

A validade dos métodos de avaliações, ou seja, a capacidade de avaliar exatamente a integração gerada também foi um desafio importante a ser alcançado. A geração de resultados semeIhantes a partir da visão de mais de um avaliador foi considerada na disciplina (possibilitada pelo uso do guia do tutor), e as estratégias diversificadas auxiliaram a diluir tal diversidade.

Nesse sentido, a aplicação de MA associado ao feedback dos discentes foi imprescindível para a tomada de decisões na continuidade da integração dos conteúdos, bem como o feedback dos docentes, considerando que a diversidade contribui para que os diversos saberes, disciplinares e pedagógicos, enriqueçam a construção das atividades propostas ${ }^{17}$.

Proporcionar espaços de feedback direciona o planejamento e ouvir os estudantes, acolhendo suas demandas e valorizando suas percepções, os tornam copartícipes no sentido de construir uma disciplina agradável e que contribua para o seu processo formativo.

As metodologias de ensino inovadoras desafiam docentes e discentes a assumirem novos papéis $^{17}$ e, após dois semestres da disciplina, é perceptível pelos estudantes que tal ação auxiliará no futuro acadêmico, e que a articulação entre os ciclos influencia na qualidade de ensino e na qualidade da formação para atuação profissional ${ }^{11}$.

Após a pandemia, haverá a necessidade de construção de uma nova base de relacionamento entre acadêmicos, professores e a Universidade. As preocupações neste momento devem estar relacionadas às condições de trabalho dos docentes, na qualidade do processo ensino-aprendizagem, na relevância dos temas abordados nas aulas, no desenvolvimento de práticas pedagógicas centradas no acadêmico, no resgate da responsabilidade do estudante sobre seu processo de aprendizagem e no envolvimento das famílias no processo de formação acadêmica ${ }^{18}$.

\section{CONCLUSÕES}

O maior aprendizado decorrente da docência num mundo em tempos de pandemia foi a necessidade de adaptação, a vontade de aprender e estar aberto ao novo, ter empatia, planejamento e criatividade, além de cuidar do outro e exercer a docência com afeto. Esta intensa reinvenção docente vivenciada neste semestre letivo atípico contribuiu para o fortalecimento da identidade docente.

Destaca-se a contribuição da Universidade ao ofertar a formação docente institucional e o apoio entre os pares, que contribuíram para o sucesso das atividades. Além disso, o aprendizado dos futuros médicos foi impactado positivamente pela aplicação de TDICs, que poderá ser ampliado futuramente para a Telemedicina, em contextos epidemiológicos de isolamento social.

Compreende-se que desprender-se de veIhos paradigmas educacionais é necessário para a introdução de novas metodologias nas escolas médicas. Afinal, se temos que formar estudantes críticos, criativos e reflexivos, como possibilitar uma educação se enquanto docente não atuarmos desta forma? A chave está na contínua formação docente para que a práxis seja constantemente fortalecida e reinventada, atributos necessários para o desenvolvimento docente para o mundo pós-pandemia.

\section{REFERÊNCIAS BIBLIOGRÁFICAS}

1. Brasil. Ministério da Educação. Conselho Nacional de Educação. Câmara de Educação Superior. Resolução No. 3 de 20 de junho de 2014. Institui Diretrizes Curriculares Nacionais do curso de graduação em Medicina e dá 
outras providências. Diário Oficial da União, Brasília, 23 junho de 2014; Seção 1, p. 8-11.

2. Carabetta Júnior V. Metodologia ativa na educação médica. RevMed. 2016;95(3)113-21.

3. Leal NO, Ferreira PEB, Macedo MAB, Souza SRG. Utilização de metodologias ativas no ensino médio brasileiro: realidade atual. Arquivos do MUDI. 2019; 23(3)432442.

4. FURB. Universidade Regional de Blumenau. Projeto Político Pedagógico do curso de Medicina. Blumenau: FURB, 2018. Disponível em: http://www.furb.br/web/ upl/graduacao/projeto_pedagogico/201906271524260. PPC\%20Medicina\%20-2018.pdf.Acesso em 25 jul 2020.

5. Gomes VTS, Rodrigues RO, Gomes RNS, Gomes MS, Viana LVM, Silva FS. A Pandemia da Covid-19: Repercussões do Ensino Remoto na Formação Médica. Rev. Bras. Educ. Med. 2020; 44(4); e114.

6. Miranda IMM, Tavares HHF, da Silva HRS, Braga MS, Santos RO, Guerra HS. Qualidade de Vida e Graduação em Medicina. Rev. Bras. Educ. Med. 2020; 44(3): e086.

7. Felisberto LCC, Giovannin PE, Diógenes ICF, Carlos LPN, Lins LFTS. O Caminho se Faz ao Caminhar: Novas Perspectivas da Educação Médica no Contexto da Pandemia. Rev. Bras. Educ. Med. 2020; 44(1):1-8.

8. Bento LMA, de Andrade LP, Sales A, de Souza AP, de Souza AFP, Batistona GT, et al. Percepção dos alunos de medicina quanto a aprendizagem $X$ ansiedade na metodologia ativa. Rev Ens Educ Cienc Human. 2017;18(2):178-182.

9. Cani JB, Sandrini EGC, Soares GM, Scalzer K. Educação e COVID-19: A arte de reinventar a escola mediando a aprendizagem "prioritariamente" pelas TDIC. Ifes Ciência [Internet]. $13^{\circ}$ de junho de 2020 [citado $14^{\circ}$ de agosto de 2020];6(1):23-39. Disponível em: https://ojs.ifes. edu.br/index.php/ric/article/view/713
10. Santana C. Saúde mental: depressão, ansiedade e estresse de estudantes de pré-vestibular para o curso de medicina. [trabalho de conclusão de curso]. Passo Fundo: Universidade Federal da Fronteira Sul; 2019.

11. Moura DTD, Foltran RS, Fraiz IC, Novak EM. Articulação entre os ciclos básico e profissionalizante: percepção dos alunos da UFPR. Rev Bras Educ Med. 2018;42(1):226-36.

12. Sangrà Morer A. Educación a distancia, educación presencial y usos de la tecnología: una tríada para el progreso educativo. Edutec-e [Internet]. 1 de janeiro de 2006 [citado 14 de agosto de 2020];0(15):a024. Disponível em: https://www. edutec.es/revista/index.php/edutec-e/article/view/541

13. Costa R, Lino MM, Souza AIJ, Lorenzini E, Fernandes GCM, Brehmer LCF, et al. Ensino de enfermagem em tempos de COVID-19: como se reinventar nesse contexto? Texto Contexto Enferm2020; 29:1-3.

14. Mourão MGM, Maciel RC, Santos MS, Mourão DM, Marques MS. Metodologias ativas na graduação médica. Motricidade. 2012; 8(2):875-81.

15. Punie $Y$, ZinnbauerD, Cabrera M. 2006. A review of the impact of ICT on learning (Luxembourg, European Commission). Disponível em: http://ftp.jrc.es/EURdoc/ JRC47246.TN.pdf.

16. Idoeta PA. 2020. Os desafios e potenciais da educação à distância, adotada às pressas em meio à quarentena. Disponível em: https://www.bbc.com/portuguese/brasil-52208723.

17. Dias-Lima A, Silva MdC, Ribeiro LCV, Bendicho MT, Guedes HTV, Lemaire DC. Avaliação, Ensinagem e Metodologias Ativas: uma experiência vivenciada no componente curricular mecanismos de agressão e de defesa, no curso de medicina da Universidade do Estado da Bahia, Brasil. Rev Bras Educ Méd. 2019;43(2):216-24.

18. Martins RX. A COVID-19 e o fim da educação à distância: um ensaio. Revista de Educação a Distância. 2020;7(1):242-56. 


\section{Contribuição dos Autores}

Participou da concepção e delineamento do trabalho, da sistematização, análise, interpretação e discussão dos dados e da revisão final do artigo: Caroline Valente, Daniela Maysa de Souza, Keila Zaniboni Siqueira Batista, Ricardo Dantas Lopes e Sara Cristiane Barauna.

Participou do levantamento bibliográfico, da elaboração do artigo e da revisão final do artigo: Ana Carolina de Melo.

\section{Conflito de Interesses}

Não há qualquer conflito de interesses dos autores nesse artigo.

Corresponding Author:

Dra Daniela Maysa de Souza

Professora Departamento Medicina FURB

danielamaysa@furb.br

Editor:

Prof. Dr Felipe Villela Gomes

Recebido: $10 / 09 / 2020$

Aprovado: $10 / 12 / 2020$

c) (i) Este é um artigo publicado em acesso aberto (Open Access) sob a licença Creative 